University of Wollongong

Research Online

Faculty of Engineering and Information

Faculty of Engineering and Information

Sciences - Papers: Part B

Sciences

2019

Preparation of Al2O3 hollow microsphere via calcining carbon template and its adsorption application

Ying Zhang

Central South University

$\mathrm{Xi} \mathrm{Li}$

University of Wollongong, Australian Nuclear Science and Technology Organisation,

x1910@uowmail.edu.au

Follow this and additional works at: https://ro.uow.edu.au/eispapers1

Part of the Engineering Commons, and the Science and Technology Studies Commons

Research Online is the open access institutional repository for the University of Wollongong. For further information contact the UOW Library: research-pubs@uow.edu.au 


\title{
Preparation of Al203 hollow microsphere via calcining carbon template and its adsorption application
}

\author{
Abstract \\ Carbon microsphere was synthesized from glucose via hydrothermal method, and then alumina hollow \\ microsphere was prepared using carbon template. At reaction time of $6 \mathrm{~h}$, the carbon sphere displayed \\ uniform diameter of $800 \mathrm{~nm}$. After removal of carbon core during calcination, it obtained $600 \mathrm{~nm}$ of $\mathrm{Y}^{-}$ \\ $\mathrm{Al}_{2} \mathrm{O}_{3}$ hollow sphere with shell thickness of $80 \mathrm{~nm}$ and surface area of $186 \mathrm{~m}^{2} / \mathrm{g}$. For adsorption of \\ methylene blue, material exhibited adsorption capacity of $26.5 \pm 1.2 \mathrm{mg} / \mathrm{g}$, fitting well with Langmuir \\ isotherm. It is demonstrated that calcining carbon template was an effective and facile approach to \\ obtain hollow sphere material. \\ Disciplines \\ Engineering | Science and Technology Studies

\section{Publication Details} \\ Zhang, Y. \& Li, X. (2019). Preparation of Al203 hollow microsphere via calcining carbon template and its \\ adsorption application. Chemical Physics Letters, 731 136589-1-136589-6.
}




\title{
Preparation of $\mathrm{Al}_{2} \mathrm{O}_{3}$ hollow microsphere via calcining carbon template and its adsorption application
}

\author{
Ying Zhang ${ }^{1}, \mathrm{Xi} \mathrm{Li}^{2,3 *}$ \\ 1 School of Mineral Processing and Bioengineering, Central South University, \\ Changsha 410083, P. R. China \\ 2 School of Mechanical, Materials, Mechatronic and Biomedical Engineering, \\ University of Wollongong, NSW 2522, Australia
}

3 Australian Nuclear Science and Technology Organisation, Lucas Heights, NSW 2234, Australia

Ying Zhang, zymissyou777@163.com

*Corresponding author. Xi Li, Tel: +61 450457795; x1910@uowmail.edu.au

\begin{abstract}
Carbon microsphere was synthesized from glucose via hydrothermal method, and then alumina hollow microsphere was prepared using carbon template. At reaction time of $6 \mathrm{~h}$, the carbon sphere displayed uniform diameter of $800 \mathrm{~nm}$. After removal of carbon core during calcination, it obtained $600 \mathrm{~nm}$ of $\gamma-\mathrm{Al}_{2} \mathrm{O}_{3}$ hollow sphere with shell thickness of $80 \mathrm{~nm}$ and surface area of $186 \mathrm{~m}^{2} / \mathrm{g}$. For adsorption of methylene blue, material exhibited adsorption capacity of $26.5 \pm 1.2 \mathrm{mg} / \mathrm{g}$, fitting well with Langmuir isotherm. It is demonstrated that calcining carbon template was an effective and facile approach to obtain hollow sphere material.
\end{abstract}

Key words: Carbon materials; $\mathrm{Al}_{2} \mathrm{O}_{3}$ hollow microsphere; Formation mechanism; Adsorption 


\section{Introduction}

Hollow micro/nanomaterial exhibits huge inside space and nanoscale shell, such as hollow sphere, hollow tube and hollow polyhedron [1,2]. Hollow material is widely used in adsorption, catalysis, hydrogen storage, electrology and mechanics [3]. Alumina $\left(\mathrm{Al}_{2} \mathrm{O}_{3}\right)$ shows many advantages [4], such as strong mechanical strength, chemical stability, perfect electrical and thermal insulation and slight toxicity.

Generally, carbon was selected as the core with coating of metal ions on its surface, and the hollow shell would be obtained after remove the carbon template [5]. Multiple methods were applied to synthesize hollow material, like sol-gel, coprecipitation, hydrothermal method, etc. $[1,3]$. Due to relatively low reaction temperature, convenient procedure and various morphologies, hydrothermal method was a facile approach, although the process was difficult to observe directly. Sun et al. [6] used hydrothermal method to synthesize carbon spheres with diameter of $150-1500 \mathrm{~nm}$, and then the carbon sphere was used as template to prepare nano $\mathrm{Au}, \mathrm{Ag}$, and Pt. Yin et al. [7] synthesized the carbon sphere template from glucose, and the $\mathrm{TiO}_{2}$ hollow spheres were prepared via sol-gel method and calcination at $500{ }^{\circ} \mathrm{C}$ in air.

In present work, hydrothermal method was used for preparation carbon microsphere from green and low cost precursor of glucose. The core-shell structure was formed with carbon core and $\mathrm{Al}^{3+}$ shell. After removal of carbon template via calcination, the as-prepared $\mathrm{Al}_{2} \mathrm{O}_{3}$ material expressed uniform and complete hollow sphere structure. Further, the application performance of material was investigated by adsorption for typical adsorbate of methylene blue solution. 


\section{Materials and methods}

\subsection{Preparation}

Typically, $8.1 \mathrm{~g}$ of anhydrous glucose (98\%) was dissolved in $75 \mathrm{~mL}$ of deionized water to form 0.6 M glucose solution. Subsequently, solution was transferred to Teflon autoclave and heated at $180{ }^{\circ} \mathrm{C}$ for 3,6 or $9 \mathrm{~h}$. After washing and drying, carbon microsphere $(\mathrm{CM})$ was synthesized. Then, $2.4 \mathrm{~g}$ of $\mathrm{CM}$ was immersed into $100 \mathrm{~mL}$ of $0.5 \mathrm{M} \mathrm{Al}\left(\mathrm{NO}_{3}\right)_{3}(98 \%)$ solution, with $6 \mathrm{~g}$ of $\mathrm{NaOH}(96 \%)$, heating at $80{ }^{\circ} \mathrm{C}$ for $12 \mathrm{~h}$. After filtration and drying, the $\mathrm{CM}$ coating with adsorbed $\mathrm{Al}^{3+}(\mathrm{Al} @ \mathrm{CM})$ was prepared. The Al@CM was heated in $\mathrm{N}_{2}$ at $5{ }^{\circ} \mathrm{C} / \mathrm{min}$ up to $400{ }^{\circ} \mathrm{C}$ for $1 \mathrm{~h}$, and then it was heated in air at $500{ }^{\circ} \mathrm{C}$ for $1 \mathrm{~h}$. Finally, the powder of $\mathrm{Al}_{2} \mathrm{O}_{3}$ hollow microsphere (AlHM) was obtained (Fig. 1). All of chemical reagents were analytical grade.

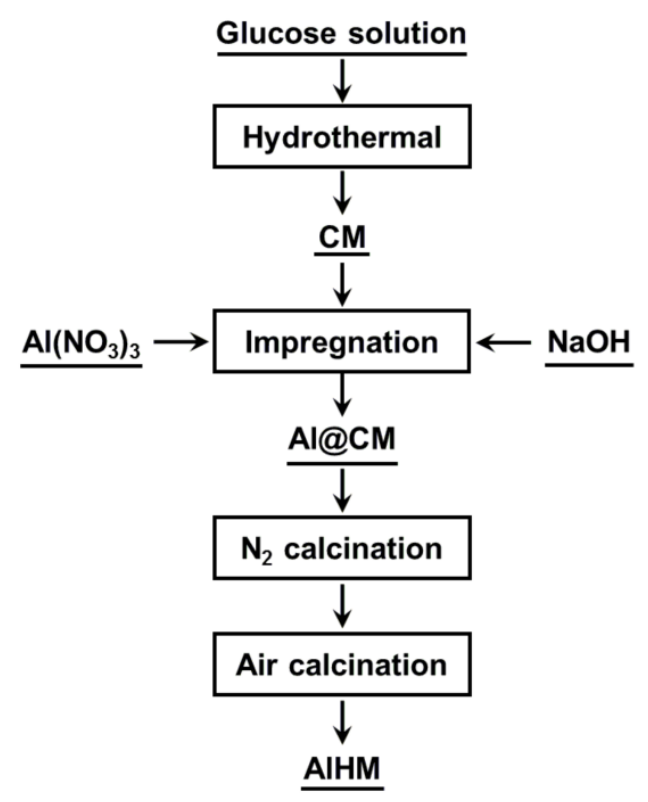

Fig. 1. Preparation flowchart of AlHM.

\subsection{Characterization}

Particle size distributions were investigated using laser particle size analyzer (Mastersizer 2000, Malvern). X-ray diffraction (XRD) was measured by a Bruker 
diffractometer (D8 Advance) using $\mathrm{Cu} K \alpha$ radiation $(\lambda=0.154 \mathrm{~nm})$ under $40 \mathrm{kV}$. Surface functional groups were examined with the Fourier transform infrared spectroscopy (FTIR) analyzer (Nexus 670, Nicolet) using KBr tablet. Textures were determined via $\mathrm{N}_{2}$ adsorption-desorption data at $-196{ }^{\circ} \mathrm{C}$ using a Quantachrome NOVA-3000 gas sorption analyzer. Surface area $\left(S_{\mathrm{BET}}\right)$ was calculated using the Brunauer-EmmettTeller (BET) method, and pore size distribution was obtained from the Barrett-JoynerHalenda (BJH) model. Surface morphology was observed by scanning electron microscope (SEM, Helios Nanolab 600i, FEI) at $5 \mathrm{kV}$ and transmission electron microscope (TEM, Tecnai G2 F20, FEI) at $200 \mathrm{kV}$.

\subsection{Adsorption}

As a typical dye, methylene blue (MB) was usually used as adsorbate in liquid adsorption to investigate mesopores and micropores. During continuous stirring adsorption at $25 \pm 1{ }^{\circ} \mathrm{C}, 0.1 \mathrm{~g}$ of $\mathrm{AlHM}$ powder were added into $100 \mathrm{~mL}$ of $\mathrm{MB}(97 \%)$ solution, with MB concentrations of 5, 10, 20, 50, 100 and $200 \mathrm{mg} / \mathrm{L}$, respectively. After $8 \mathrm{~h}$ for adsorption equilibrium, the MB concentration was determined using an UV1800 ultraviolet spectrophotometer (Shanghai AUCY) at $660 \mathrm{~nm}$. Adsorption capacity $q_{\mathrm{e}}$ (mg/g) of MB was calculated using the following Eq. 1:

$$
q_{\mathrm{e}}=\frac{\left(C_{0}-C_{\mathrm{e}}\right) \cdot V}{m}
$$

where $C_{0}$ and $C_{\mathrm{e}}$ are initial and equilibrium concentrations of $\mathrm{MB}(\mathrm{mg} / \mathrm{L})$, respectively; $V$ is volume of solution (L) and $m$ is mass of AlHM sample $(\mathrm{g})$.

For kinetic studies, the linear pseudo first-order model Eq. 2 and pseudo second-order model Eq. 3 were presented as [8]: 


$$
\begin{gathered}
\ln \left(q_{\mathrm{e} 1}-q_{\mathrm{t}}\right)=\ln q_{\mathrm{e} 1}-K_{1} \cdot t \\
\frac{t}{q_{\mathrm{t}}}=\frac{1}{K_{2} \cdot q_{\mathrm{e} 2}^{2}}+\frac{t}{q_{\mathrm{e} 2}}
\end{gathered}
$$

where $q_{\mathrm{e} 1}(\mathrm{mg} / \mathrm{g})$ and $q_{\mathrm{e} 2}(\mathrm{mg} / \mathrm{g})$ are equilibrium capacities of corresponding kinetic models, $q_{\mathrm{t}}(\mathrm{mg} / \mathrm{g})$ is adsorption capacity at certain time; $K_{1}(\mathrm{mg} /(\mathrm{g} \cdot \mathrm{h}))$ and $K_{2}(\mathrm{mg} /(\mathrm{g} \cdot \mathrm{h}))$ are corresponding speed constants; $t(\mathrm{~h})$ is adsorption time. Further, the fitting results were investigated using correlation coefficient of $R^{2}$.

For classic Langmuir (homogenous monolayer adsorption, Eq. 4) and Freundlich (heterogeneous multilayer adsorption, Eq. 5) isotherms, the equations were expressed as followings [8]:

$$
\begin{gathered}
q_{\mathrm{e}}=\frac{q_{\mathrm{m}} \cdot K_{\mathrm{L}} \cdot C_{\mathrm{e}}}{1+K_{\mathrm{L}} \cdot C_{\mathrm{e}}} \\
q_{\mathrm{e}}=K_{\mathrm{F}} \cdot C_{\mathrm{e}}^{\frac{1}{n}}
\end{gathered}
$$

where $q_{\mathrm{m}}(\mathrm{mg} / \mathrm{g})$ is monolayer adsorption capacity for Langmuir equation; $n$ is dimensionless heterogeneity factor for Freundlich equation; $K_{\mathrm{L}}(\mathrm{L} / \mathrm{mg})$ and $K_{\mathrm{F}}$ $(\mathrm{mg} / \mathrm{g})(\mathrm{mg} / \mathrm{L})^{n}$ are constants of Langmuir and Freundlich equations, respectively.

\section{Results and discussion}

\subsection{Morphology}

Microstructures of samples are shown in Fig. 2. The CM 3h (Fig. 2a) displayed an aggregated spherical structure, with average diameter of $\sim 500 \mathrm{~nm}$. Under longer hydrothermal time of $6 \mathrm{~h}$ in Fig. $2 \mathrm{~b}$, microspheres became relatively uniform and individual sphere. In illustration, the CM 6h showed smooth surface with larger size of $\sim 800 \mathrm{~nm}$ [7]. For CM 9h in Fig. 2c, the microspheres grew larger and expressed wide 
particle size distribution, with size of $800-1500 \mathrm{~nm}$. Besides, several microspheres became cracked. As shown in Fig. 2d for AlHM from CM 6h, it still maintained the spherical structure, while the surface became pleated and squamous structure after calcination [7]. Due to the thermal shrinkage at $500{ }^{\circ} \mathrm{C}$ [9], its diameter was reduced from $\sim 800 \mathrm{~nm}$ (CM template) to $\sim 600 \mathrm{~nm}$. For TEM image in Fig. 2e, there was uniform sphere structure for $\mathrm{CM}$ 6h. After calcination for AlHM 6h in Fig. 2f, it exhibited apparent hollow structure with shell thickness of $\sim 80 \mathrm{~nm}$. Fig. $2 \mathrm{~g}$ and $\mathrm{h}$ display mapping of $\mathrm{Al} @ \mathrm{CM}$ 6h and corresponding AlHM. There were uniform distributions of $\mathrm{C}, \mathrm{O}$ and $\mathrm{Al}$ elements on surface of $\mathrm{Al} @ \mathrm{CM}$. After calcination, $\mathrm{Al}^{3+}$ layer changed to $\mathrm{Al}_{2} \mathrm{O}_{3}$ shell and $\mathrm{CM}$ pyrolyzed [10], leaving $\mathrm{Al}$ and $\mathrm{O}$ elements.

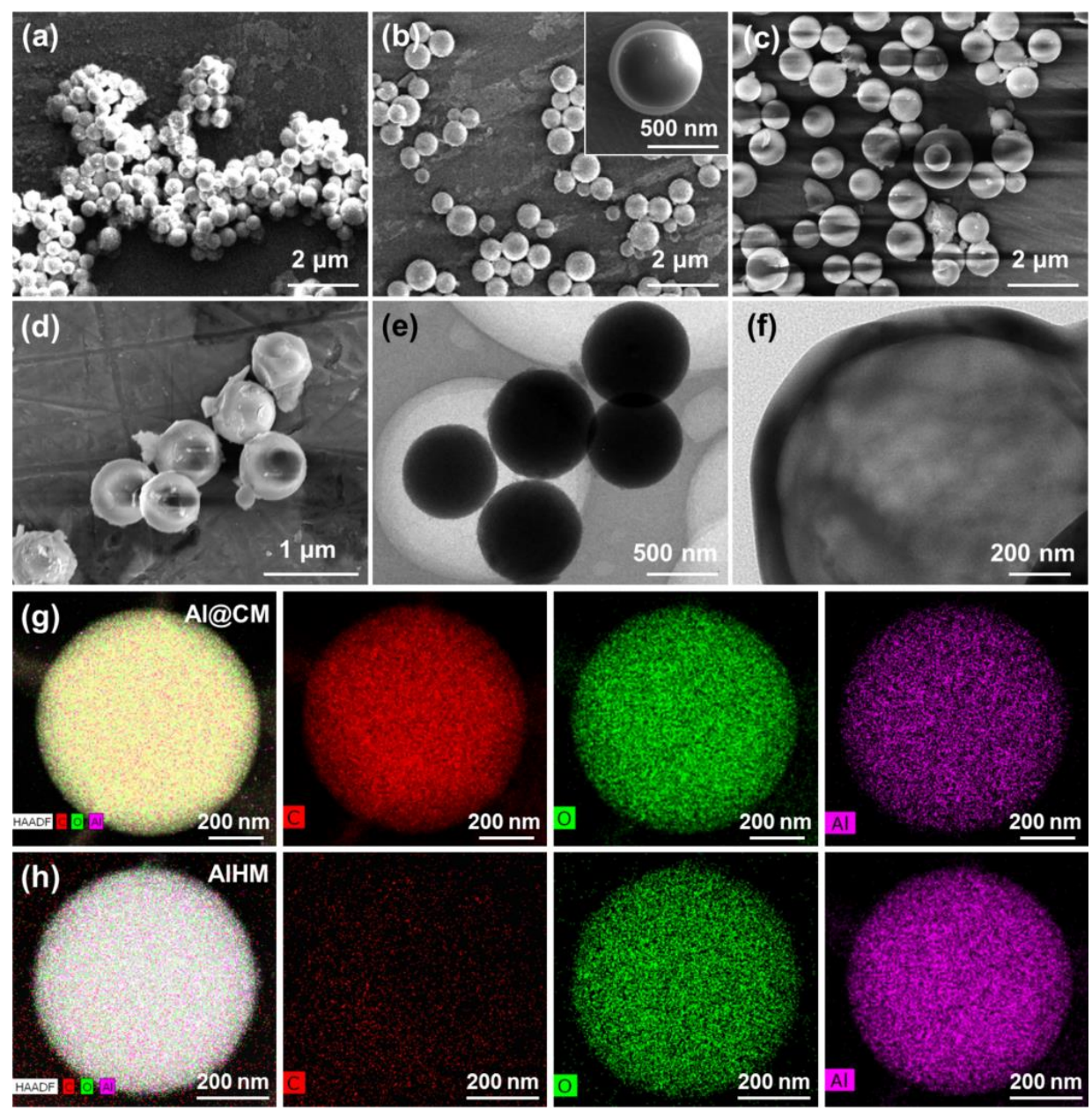

Fig. 2. SEM images of (a) CM 3h, (b) CM 6h, (c) CM 9h, (d) AlHM 6h, TEM images of (e) CM 6h, (f) AlHM 6h; (g,h) mapping of Al@CM and AlHM 6h. 


\subsection{Physical properties}

Particle size distributions of CM 3-9h and AlHM are shown in Fig. 3a. Under short reaction time of $3 \mathrm{~h}$, the $\mathrm{CM}$ expressed relatively small size, with average diameter of $520 \mathrm{~nm}$. With prolonging time to 6h, the CM grew larger and distributed uniformly [10], locating around $810 \mathrm{~nm}$. At hydrothermal time of $9 \mathrm{~h}$, the $\mathrm{CM}$ presented wide size distribution, with peak value size of $\sim 1100 \mathrm{~nm}$. Due to relatively uniform size and smooth surface, the CM 6h was selected as template for preparing Al@CM. For AlHM from, it still remained relatively narrow size distribution, and its diameter was reduced to $630 \mathrm{~nm}$ due to thermal shrinkage during calcination [9].

Fig. $3 b$ expresses the XRD patterns of samples. One broad peak at approximately $2 \theta=22^{\circ}$ was observed and was ascribed to the (002) plane of carbon, presenting typical amorphous structure of $\mathrm{CM}[11]$. After immersed in $\mathrm{Al}\left(\mathrm{NO}_{3}\right)_{3}$ solution, the $\mathrm{Al} @ \mathrm{CM}$ pattern became flat and three new peaks occurred at $2 \theta=18,20$ and $40^{\circ}$, assigning to reflection of the (001), (100) and (-1-10) planes of $\beta$-Al(OH) 3 (JCPDS 77-0114) [12]. The reason was that $\mathrm{Al}^{3+}$ were adsorbed on surface of $\mathrm{CM}$, and subsequently formed $\mathrm{Al}(\mathrm{OH})_{3}$ with $\mathrm{NaOH}$. After calcination under $\mathrm{N}_{2}$ and air, several new peaks located at $2 \theta=38^{\circ}, 46^{\circ}$ and $67^{\circ}$, ascribing to the (440), (400) and (311) planes of $\gamma-\mathrm{Al}_{2} \mathrm{O}_{3}$ (JCPDS 80-1385) [12]. The presence of $\mathrm{Al}_{2} \mathrm{O}_{3}$ originated from the pyrolysis of $\mathrm{Al}(\mathrm{OH})_{3}$ during calcination [10].

The FTIR spectra of materials are presented in Fig. 3c. A wide peak around 3400 $\mathrm{cm}^{-1}$ was assigned to stretching vibration of $-\mathrm{OH}$ bond. Peaks of 1720 and $1630 \mathrm{~cm}^{-1}$ were stretching vibration of $\mathrm{C}=\mathrm{O}$ and $\mathrm{C}=\mathrm{C}$, respectively [13]. While for AlHM, these two peaks almost disappeared, signifying the removal of CM template. A new peak at $1390 \mathrm{~cm}^{-1}$ in $\mathrm{Al} @ \mathrm{CM}$ spectrum could be attributed to stretching vibration of $\mathrm{NO}_{3}^{-}$in adsorbed $\mathrm{Al}\left(\mathrm{NO}_{3}\right)_{3}$ [14]. Similarly, a weak peak around $1080 \mathrm{~cm}^{-1}$ was bending 
vibration of $\mathrm{Al}-\mathrm{OH}$ [14]. In AlHM spectrum, several significant peaks located at $600-$ $800 \mathrm{~cm}^{-1}$ were attributed to vibrations of $\mathrm{Al}-\mathrm{O}$ bond in $\left[\mathrm{AlO}_{6}\right]$ octahedra [10].

Fig. 3d expresses the $\mathrm{N}_{2}$ adsorption-desorption isotherms for AlHM. According to IUPAC classification, sample presented the type IV isotherm with hysteresis loop for mesopores [9]. Using the BET method, AlHM 6h displayed moderate surface area of $186 \mathrm{~m}^{2} / \mathrm{g}$. Total pore volume was given as $0.302 \mathrm{~cm}^{3} \mathrm{~g}^{-1}$, deriving from relative pressure $P / P_{0}$ of $\sim 0.99$. As seen from BJH pore size distribution, the sample exhibited hybrid pore structure of micropores and mesopores, with a peak value of $\sim 4 \mathrm{~nm}$. The $S_{\mathrm{BET}}$ values of AlHM prepared from CM 3h and CM 9h were 142 and $165 \mathrm{~m}^{2} / \mathrm{g}$, respectively.
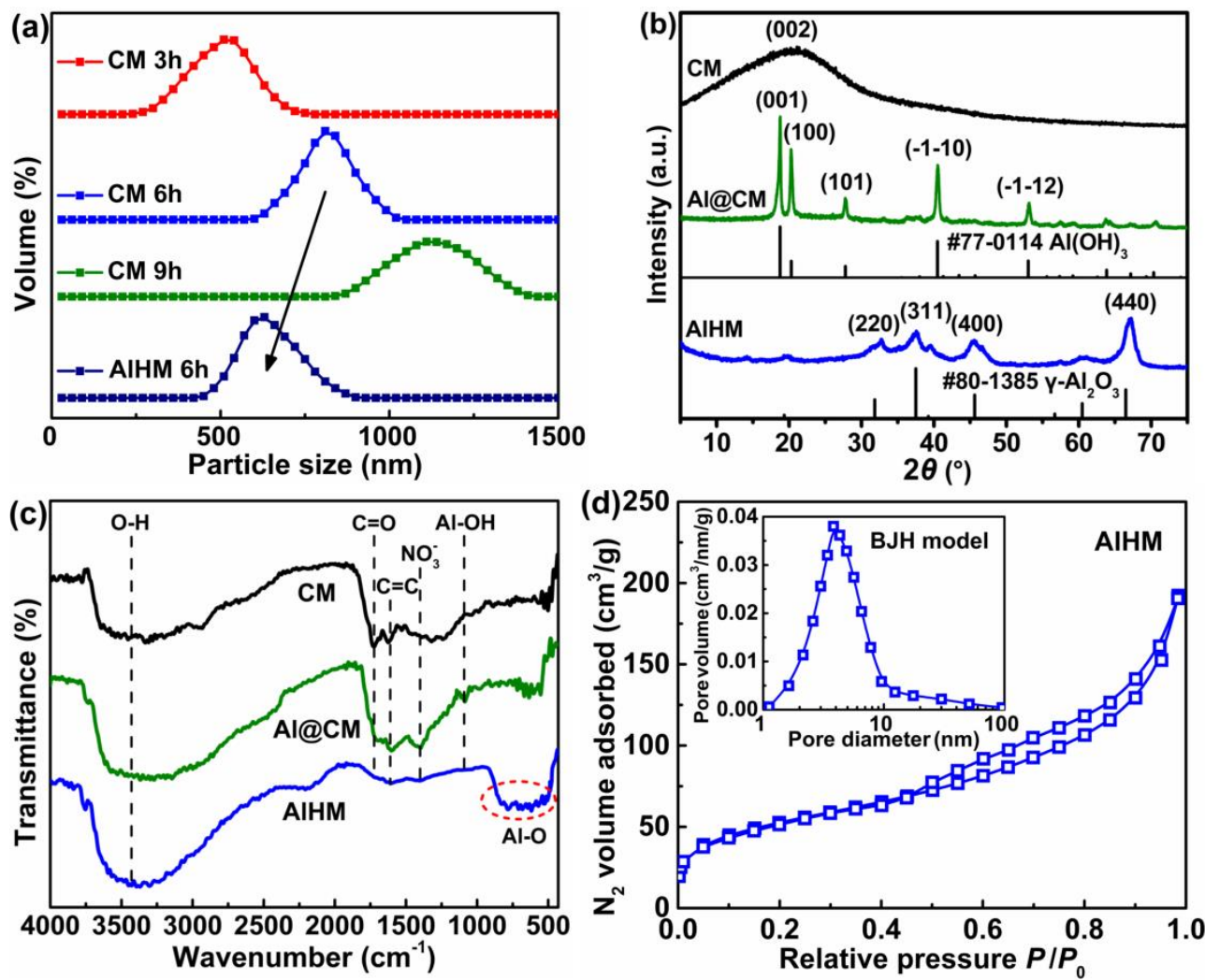

Fig. 3. (a) particle size distribution of CM and AlHM, (b) XRD patterns of CM, Al@CM and AlHM, (c) FTIR spectra of CM, Al@CM and AlHM, (d) adsorption-desorption isotherms of $\mathrm{N}_{2}$ for AlHM. 


\subsection{Formation mechanism}

The formation process of AlHM is explained in Fig. 4. Based on carbon source of glucose, the CM was synthesized via hydrothermal method. Then, CM was immersed into $\mathrm{Al}\left(\mathrm{NO}_{3}\right)_{3}$ solution, and $\mathrm{Al}^{3+}$ could be adsorbed on its surface. With effect of $\mathrm{NaOH}$, the $\mathrm{Al}^{3+}$ became form of $\mathrm{Al}(\mathrm{OH})_{3}$ (Eq. 6) and formed the $\mathrm{Al}(\mathrm{OH})_{3}$ coating of $\mathrm{Al} @ \mathrm{CM}$. When heating in $\mathrm{N}_{2}$ at $400{ }^{\circ} \mathrm{C}$, the $\mathrm{Al}(\mathrm{OH})_{3}$ would be pyrolyzed and turn into the $\mathrm{Al}_{2} \mathrm{O}_{3}$ (Eq. 7), while CM template was maintained at this time. During subsequent calcination in air at $500{ }^{\circ} \mathrm{C}$, the $\mathrm{CM}$ was oxidized to $\mathrm{CO}_{2}$, leaving the $\mathrm{Al}_{2} \mathrm{O}_{3}$ shell of $\mathrm{AlHM}$ [10]. In adsorption experiment, the MB molecule could enter into pores of porous AlHM.

$$
\begin{gathered}
\mathrm{Al}^{3+}+3 \mathrm{OH}^{-} \rightarrow \mathrm{Al}(\mathrm{OH})_{3} \\
2 \mathrm{Al}(\mathrm{OH})_{3} \rightarrow \mathrm{Al}_{2} \mathrm{O}_{3}+3 \mathrm{H}_{2} \mathrm{O}
\end{gathered}
$$

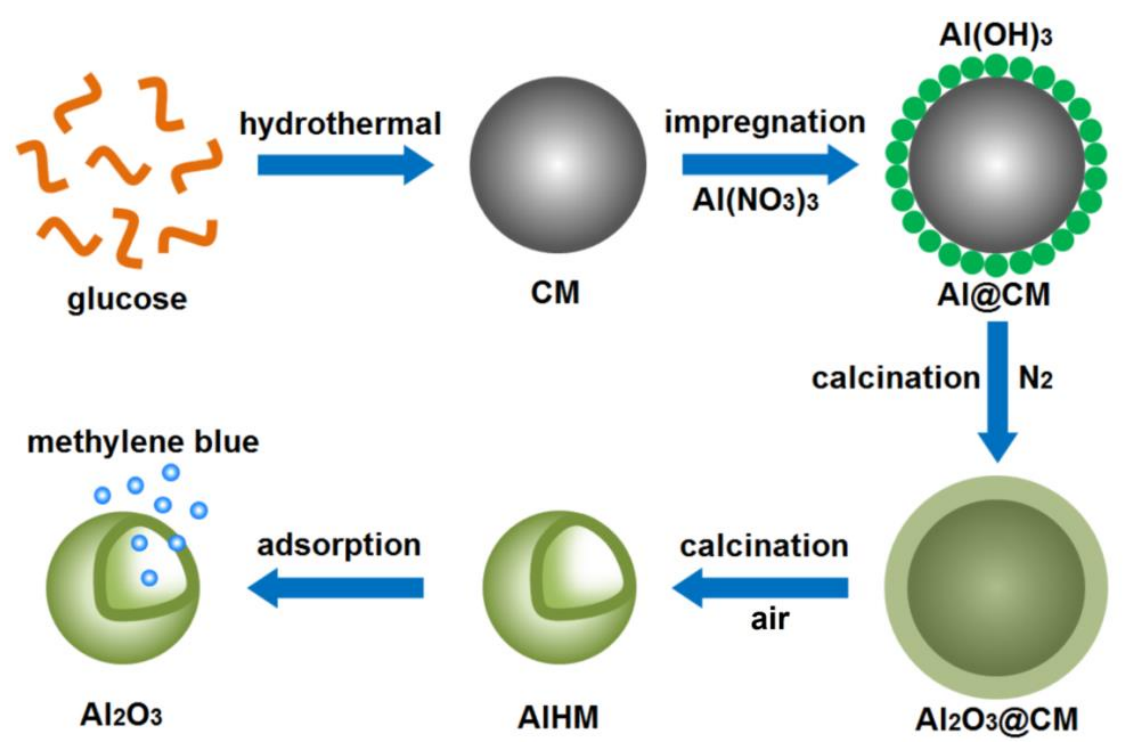

Fig. 4. Formation mechanism of AlHM.

\subsection{Adsorption performance}

Fig. 5a exhibits the adsorption capacity of MB onto AlHM 6h during prolonged time. With the increasement of $\mathrm{MB}$ concentration, the adsorption capacity $q_{\mathrm{t}}$ was also increased. During the initial $0.5 \mathrm{~h}$, the adsorption behavior was fast and $q_{\mathrm{t}}$ values 
increased rapidly; while during subsequent time, the adsorption speed became slow and $q_{\mathrm{t}}$ values increased gently. It could be considered that at time of $4 \mathrm{~h}$, the adsorption process was closed to equilibrium status [15].

Kinetic and isotherm were used to investigate the MB adsorption onto AlHM. The parameters of kinetic equations are listed in Table 1. The pseudo second-order model expressed better fitting results with $R^{2}$ of 0.999 than pseudo first-order model. Fig. $5 \mathrm{~b}$ displays linear pseudo second-order model of MB adsorption onto AlHM 6h. Due to large $R^{2}$, the pseudo second-order model showed good accuracy with experimental data. This fact suggested that the adsorption speed was mainly dependent on adsorption sites of AlHM rather than the MB concentration in solution [15].

Plots of two isotherms for MB adsorption onto AlHM 6h are expresses in Fig. 5c. With the increasement of equilibrium concentration $C_{\mathrm{e}}$, the adsorption capacity $q_{\mathrm{e}}$ was increased rapidly and then became almost stable. Under the initial concentration of 200 $\mathrm{mg} / \mathrm{L}$, the maximum $q_{\mathrm{e}}$ value of $\mathrm{MB}$ was reached as $26.5 \pm 1.2 \mathrm{mg} / \mathrm{g}$, larger than 8.38 $\mathrm{mg} / \mathrm{g}$ of $\mathrm{Al}_{2} \mathrm{O}_{3}$ hollow sphere in previous report [15]. For the Langmuir model, it presented better $R^{2}$ of 0.997 than 0.939 of Freundlich model, implying the type of monolayer adsorption [13]. Table 2 lists the parameters of these two isotherms.

At MB concentration of $200 \mathrm{mg} / \mathrm{L}$, the $q_{\mathrm{e}}$ values of AlHM 3h and 9h were recorded as $20.1 \pm 0.9$ and $23.2 \pm 1.1 \mathrm{mg} / \mathrm{g}$, respectively. The adsorption performances of MB were also investigated using other typical adsorption materials, such as $180 \mathrm{mg} / \mathrm{g}$ for graphene aerogel [13], $423 \mathrm{mg} / \mathrm{g}$ for activated carbon [16], and $95 \mathrm{mg} / \mathrm{g}$ for porous $\mathrm{TiO}_{2}$ [17]. Fig. 5d presents the relationship between surface area $S_{\mathrm{BET}}$ and adsorption capacity $q_{\mathrm{e}}$ from this work and literatures. It could be found that the surface area displayed significant positive correlation for adsorption capacity, with high $R^{2}$ of 0.922 . 

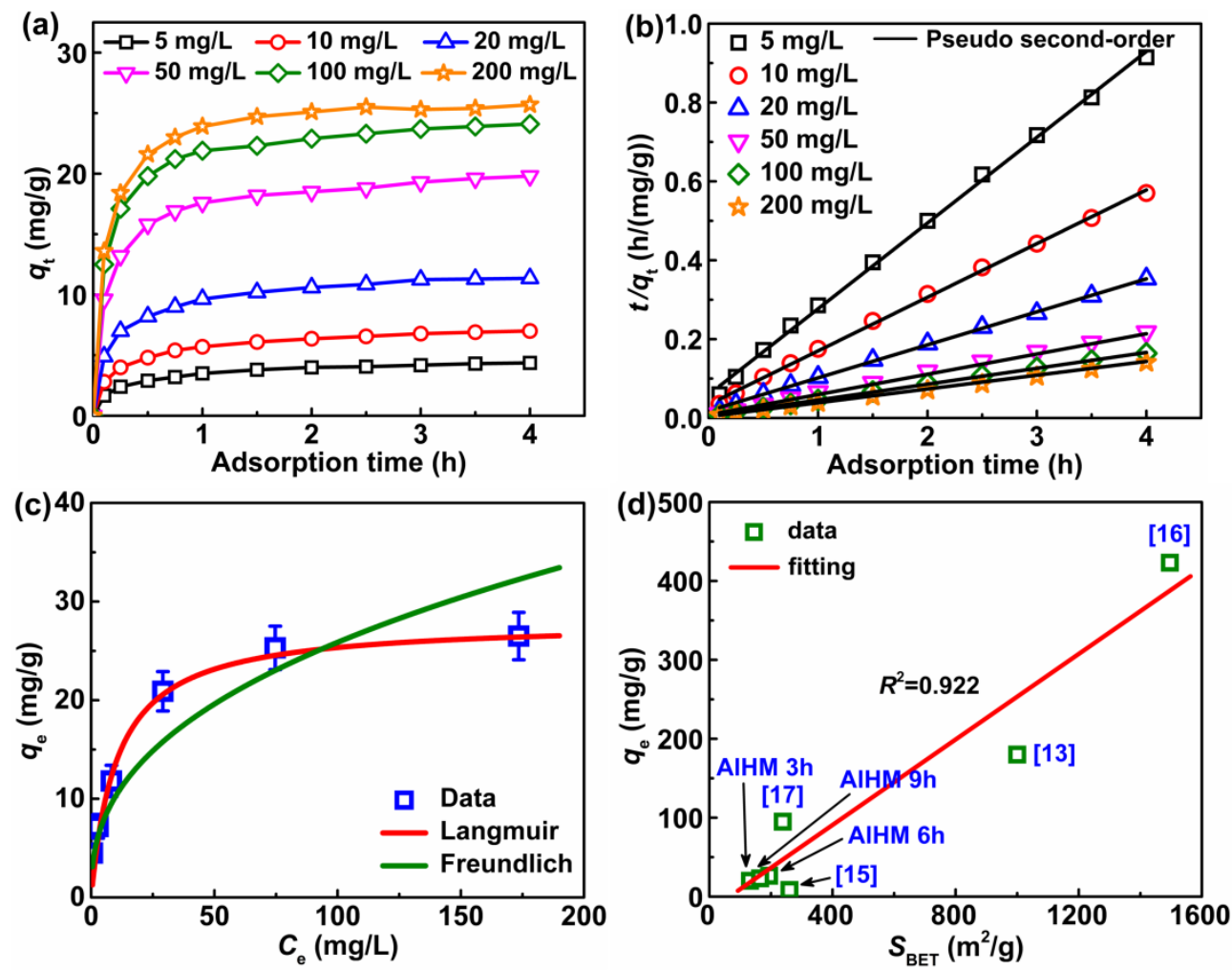

Fig. 5. MB adsorption onto AlHM 6h: (a) adsorption capacity during prolonged time; (b) pseudo second-order fitting; (c) two adsorption isotherms with error bar; (d) relationship between surface area and adsorption capacity.

Table 1 Parameters of kinetics equations for MB adsorption onto AlHM 6h.

\begin{tabular}{ccccccc}
\hline \multirow{2}{*}{$C_{0}$ of MB } & \multicolumn{3}{c}{ Pseudo first-order model } & \multicolumn{3}{c}{ Pseudo second-order model } \\
\cline { 2 - 7 }$(\mathrm{mg} / \mathrm{L})$ & $q_{\mathrm{e} 1}(\mathrm{mg} / \mathrm{g})$ & $K_{1}\left(\mathrm{~h}^{-1}\right)$ & $R^{2}$ & $q_{\mathrm{e} 2}(\mathrm{mg} / \mathrm{g})$ & $K_{1}(\mathrm{~g} /(\mathrm{mgh}))$ & $R^{2}$ \\
\hline 5 & 2.3 & 0.708 & 0.945 & 4.6 & 0.796 & 0.999 \\
10 & 3.6 & 0.731 & 0.936 & 7.4 & 0.543 & 0.999 \\
20 & 5.4 & 0.712 & 0.917 & 11.9 & 0.385 & 0.999 \\
50 & 7.5 & 0.535 & 0.919 & 20.4 & 0.312 & 0.999 \\
\hline
\end{tabular}


100

8.0

0.562

0.918

24.9

0.301

0.998

200

8.2

0.625

0.860

26.3

0.371

0.998

Table 2 Coefficients of isotherm models for MB adsorption.

\begin{tabular}{cccc}
\hline Isotherms & \multicolumn{2}{c}{ Parameters } & $R^{2}$ \\
\hline Langmuir & $K_{\mathrm{L}=0.133 \mathrm{~L} / \mathrm{mg}}$ & $q_{\mathrm{m}}=27.6 \mathrm{mg} / \mathrm{g}$ & 0.997 \\
Freundlich & $K_{\mathrm{F}=5.70(\mathrm{mg} / \mathrm{g})(\mathrm{mg} / \mathrm{L})^{n}}$ & $n=3.03$ & 0.939 \\
\hline
\end{tabular}

\section{Conclusion}

The CM was synthesized by hydrothermal method under time of 3-9 h using glucose, and then it was selected as template to form core-shell structure of Al@CM. At hydrothermal time of $6 \mathrm{~h}$, the CM displayed relatively uniform particle size distribution with diameter of $\sim 800 \mathrm{~nm}$. After calcination in $\mathrm{N}_{2}$ and air, the CM core was shrank and volatilized, leaving $\gamma-\mathrm{Al}_{2} \mathrm{O}_{3}$ shell (AlHM) with diameter of $\sim 600 \mathrm{~nm}$ and shell thickness of $80 \mathrm{~nm}$. Due to the high $S_{\mathrm{BET}}$ value of $186 \mathrm{~m}^{2} / \mathrm{g}$, the AlHM exhibited large adsorption capacity of $26.5 \pm 1.2 \mathrm{mg} / \mathrm{g}$ for MB solution. It could be believed that this study will provide an effective and low cost approach to prepare some metal oxides with hollow sphere structure.

\section{Acknowledgements}

This work was supported by Fundamental Research Funds for Central Universities of Central South University (2017zzts108). 


\section{Conflicts of interest}

Declarations of interest: none.

\section{References}

[1] Y. Li, J. Shi, Hollow-structured mesoporous materials: chemical synthesis, functionalization and applications, Adv. Mater. 26 (2014) 3176-3205.

[2] S. Sarti, F. Bordi, Polymeric hollow micro and nanospheres for biotechnological applications: A focused review, Mater. Lett. 109 (2013) 134-139.

[3] Y. Si, M. Chen, L. Wu, Syntheses and biomedical applications of hollow micro-/nano-spheres with large-through-holes, Chem. Soc. Rev. 45 (2016) 690-714.

[4] S. Mallakpour, E. Khadem, Recent development in the synthesis of polymer nanocomposites based on nano-alumina, Prog. Polym. Sci. 51 (2015) 74-93.

[5] Y. Xia, R. Mokaya, Hollow spheres of crystalline porous metal oxides: A generalized synthesis route via nanocasting with mesoporous carbon hollow shells, J. Mater. Chem. 15 (2005) 3126-3131.

[6] X. Sun, Y. Li, Colloidal carbon spheres and their core/shell structures with noble-metal nanoparticles, Angew. Chem. Int. Edit. 43 (2004) 597-601.

[7] H. Yin, X. Wang, L. Wang, Q.L. Nie, Y. Zhang, Q. Yuan, W. Wu, Ag/AgCl modified self-doped $\mathrm{TiO}_{2}$ hollow sphere with enhanced visible light photocatalytic activity, J. Alloys Compd. 657 (2016) 44-52.

[8] J. So, C. Pang, H. Dong, P. Jang, J. U, K. Ri, C. Yun, Adsorption of 1-naphthyl methyl carbamate in water by utilizing a surface molecularly imprinted polymer, 
Chem. Phys. Lett. 699 (2018) 199-207.

[9] Z. Zhou, S.L. Chen, D. Hua, Z.G. Wang, A.C. Chen, W.H. Wang, Tailored ordered porous alumina with well-defined and uniform pore-structure, Chem. Eng. J. 223 (2013) 670-677.

[10] S. Lan, N. Guo, L. Liu, X. Wu, L. Li, S. Gan, Facile preparation of hierarchical hollow structure gamma alumina and a study of its adsorption capacity, Appl. Surf. Sci. 283 (2013) 1032-1040.

[11] Y. Zhang, L. Liu, P. Zhang, J. Wang, M. Xu, Q. Deng, Z. Zeng, S. Deng, Ultra-high surface area and nitrogen-rich porous carbons prepared by a low-temperature activation method with superior gas selective adsorption and outstanding supercapacitance performance, Chem. Eng. J. 355 (2019) 309-319.

[12] C. Hu, T. Peng, X. Hu, Y. Nie, X. Zhou, J. Qu, H. He, Plasmon-induced photodegradation of toxic pollutants with $\mathrm{Ag}-\mathrm{AgI} / \mathrm{Al}_{2} \mathrm{O}_{3}$ under visible-light irradiation, J. Am. Chem. Soc. 132 (2010) 857-862.

[13] C. Liu, H. Liu, A. Xu, K. Tang, Y. Huang, C. Lu, In situ reduced and assembled three-dimensional graphene aerogel for efficient dye removal, J. Alloys Compd. 714 (2017) 522-529.

[14] G. Li, Y. Liu, C. Liu, Solvothermal synthesis of gamma aluminas and their structural evolution, Microporous Mesoporous Mater. 167 (2013) 137-145.

[15] J. Fang, X. Huang, X. Ouyang, Xun Wang, Study of the preparation of $\gamma-\mathrm{Al}_{2} \mathrm{O}_{3}$ nano-structured hierarchical hollow microspheres with a simple hydrothermal synthesis using methylene blue as structure directing agent and their adsorption 
enhancement for the dye, Chem. Eng. J. 270 (2015) 309-319.

[16] K.Y. Foo, B.H. Hameed, Mesoporous activated carbon from wood sawdust by $\mathrm{K}_{2} \mathrm{CO}_{3}$ activation using microwave heating, Bioresour. Technol. 111 (2012) 425432.

[17] J. Feng, J. Zhu, W. Lv, J. Li, W. Yan, Effect of hydroxyl group of carboxylic acids on the adsorption of Acid Red G and Methylene Blue on $\mathrm{TiO}_{2}$, Chem. Eng. J. 269 (2015) 316-322. 